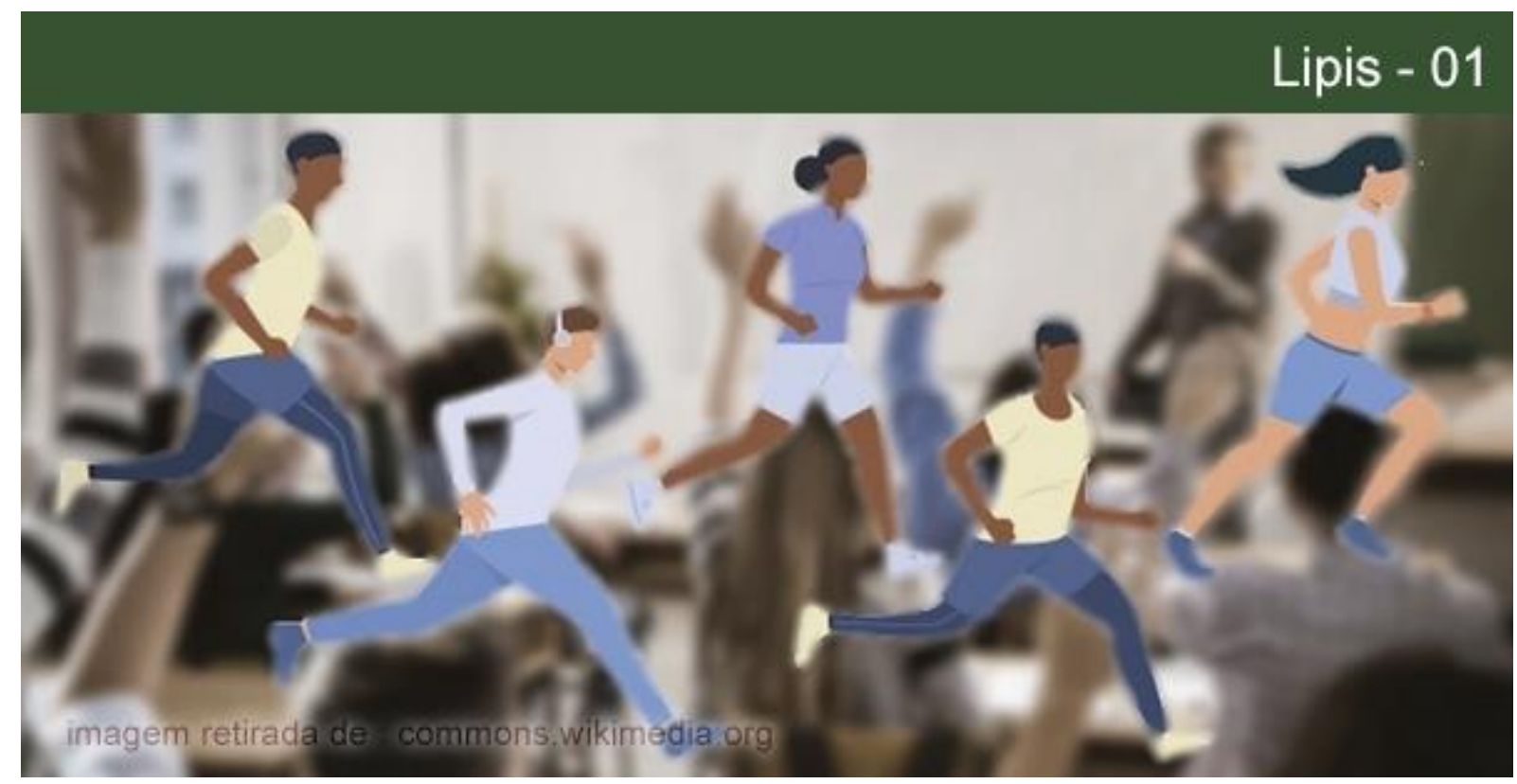

\title{
VIDA À SOMBRA DE IMAGENS: ESPETACULARIZAÇÃO DO ESPORTE NA JUVENTUDE ESCOLARIZADA
}

\section{Carlos Mendes Rosa}

Professor Adjunto do Curso de Psicologia da Universidade Federal do Tocantins (UFT-Miracema). Doutor em Psicologia Clínica pela Pontifícia Universidade Católica (PUC-Rio). E-mail: carlosmendes@mail.uft.edu.br.

\section{José Fernando Patiño Torres}

Professor Adjunto do Curso de Psicologia da Universidade Federal do Tocantins (UFT-Miracema). Doutor em Educação pela Universidade de Brasília (UnB). E-mail: jfpatinotorres@outlook.com.

\section{Emilly Kelem Sousa Silva}

Graduanda do Curso de Psicologia da Universidade Federal do Tocantins (UFT-Miracema). E-mail: kelem.emilly150@gmail.com.

\section{Sara Santos Dias Costa}

Graduanda do Curso de Psicologia da Universidade Federal do Tocantins (UFT-Miracema). E-mail: sahcosta_@hotmail.com.

Resumo: O presente artigo tem como objetivo primordial propor uma discussão acerca da espetacularização da vida cotidiana, a partir de alguns registros como: o corpo, adornado para ser exibido; a saúde, posta como obrigação moral; e a visibilidade performática, com ênfase nos atletas de alto rendimento e praticantes de esporte. Este estudo teve por base a pesquisa qualitativa, na qual se consideram os aspectos singulares e particulares das narrativas dos sujeitos participantes da pesquisa. Participaram 27 estudantes secundaristas de duas turmas do terceiro ano regular do Ensino Médio, do turno matutino, de um Colégio Estadual localizado na cidade de Miracema do Tocantins TO. Utilizou-se o Grupo Focal como técnica de coleta e análise de dados. Esse método possibilitou maior interação entre participantes e pesquisador. O conteúdo reunido foi analisado, posteriormente, sob a ótica da Teoria das Representações Sociais. Os resultados evidenciaram que o esporte, mostrado pela mídia, está diretamente ligado à uma lógica do espetáculo, como também à ideia ilusória de que ser saudável está atrelado ao corpo denominado perfeito - fitness. Tais estereótipos são expressos por marcadores sociais de gênero e somente possíveis de serem mostrados e exibidos, quando submetidos ao padrão de beleza hegemônico. Além disso, ficou evidente no imaginário social partilhado que somente há um investimento em relação ao esporte, quando esportistas já

\section{POLÊM!CA $\mid$ LABORE (}

Polêmica - Revista Eletrônica da Uerj - Rua São Francisco Xavier, 524, $1^{\circ}$ andar bloco D, sl.1001 • Tels.: +55 21 2334-4088 / 4087 • http://www.e-publicacoes.uerj.br/index.php/polemica/index http://www.labore.uerj.br • laboreuerj@yahoo.com.br 
apresentam resultados significativos para serem exibidos pelos veículos de comunicação, relevando um modelo derrota/vitória capitaneado pela visibilidade performática.

Palavras-chaves: Espetacularização. Corpo. Saúde. Esporte.

\section{LIFE IN THE SHADOW OF IMAGES: SPECTACULARIZATION OF SPORT IN SCHOOL YOUTH}

Abstract: This article aims to propose a discussion about the spectacularization of everyday life from some records such as the body, adorned to be exposed; health, posed as a moral obligation; and performance visibility, with an emphasis on high performance athletes and sports practitioners. This study was based on qualitative research, which considers the singular and particular aspects of the narratives of the research participants. Participated in this research 27 high school students from two classes of the third regular year of high school, in the morning journey, from a State College located in the city of Miracema do Tocantins - TO. For data collection, the Focal Group was performed as the data collection and analysis technique. This allowed greater interaction between participants and researchers, and its content was later seen from the perspective of the Theory of Social Representations. The results showed that the sport, shown by the media, is directly linked to the logic of the spectacle, as well as the illusory idea that being healthy is linked to the body called perfect - fitness. Such stereotypes are expressed by social gender markers, and can only be shown and exposed when subjected to the hegemonic beauty standard. Moreover, it was evident in the shared social imagination that there is only an investment in relation to sport when sportsmen already present significant results to be exposed by the media, revealing a defeat/victory model and dominated by performance visibility.

Keywords: Spectacularization. Body. Health. Sport.

\section{Introdução}

O presente trabalho foi desenvolvido durante o projeto de pesquisa "Corpo no esporte contemporâneo", da Universidade Federal do Tocantins - campus Miracema, objetivando abordar a espetacularização da vida cotidiana, a partir de alguns registros, como: o corpo, estilizado para ser mostrado; a saúde, vista como obrigação moral; e a visibilidade performática, com ênfase em atletas de alto rendimento e praticantes de esporte.

A temática espetacularização da vida tem aparecido com frequência em trabalhos científicos nos últimos anos. Guy Debord (1931-1994) é referência para se pensar o conceito, pois foi pioneiro na temática, ao escrever, em 1967, o livro A sociedade do espetáculo. Vive-se um momento em que a mídia, através da exposição exacerbada da imagem, falsifica a experimentação real do mundo, ao posicionar os indivíduos como espectadores e consumidores passivos de imagens:

[...] quanto mais ele [o indivíduo] contempla, menos vive; quanto mais aceita reconhecer-se nas imagens dominantes da necessidade, menos compreende sua própria existência e seu próprio desejo [...] É por isso que o espectador não se sente em casa em lugar algum, pois o espetáculo está em toda parte (DEBORD, 1997, p. 24-26).

É imprescindível destacar que o presente trabalho, ao fundamentar-se em Guy Debord, para discutir o que se refere à espetacularização da vida, entende o espetáculo não como abuso do mundo da visão ou produto de técnicas de propagação massiva de imagens, mas sim como

\section{POLÊM!CA $\mid$ LABORE}

Polêmica - Revista Eletrônica da Uerj - Rua São Francisco Xavier, 524, $1^{\circ}$ andar bloco D, sl.1001 • Tels.: +55 21 2334-4088 / 4087 • http://www.e-publicacoes.uerj.br/index.php/polemica/index http://www.labore.uerj.br • laboreuerj@yahoo.com.br 
uma relação social entre sujeitos mediados por imagens. Em outras palavras, "é o coração da irrealidade da sociedade real" (DEBORD, 1997, p. 16).

A vida cotidiana se tornou espetacularizada, de maneira que os sujeitos se submetem ao exibicionismo em e para mídias e/ou redes sociais. Há uma evidente degradação do "ser" em "ter": para ser alguém, há que se ter um corpo bem modelado, posição, dinheiro e bens. Tais atributos garantem a inserção social do sujeito e são os adereços de poder que se tornam definidores de seu ser e de seu valor (VILHENA; MEDEIROS; NOVAES, 2005). E, na atual sociedade, vê-se ainda que o "parecer" (ser ou ter algo) torna-se suficiente para a maioria dos sujeitos e a possibilidade de compartilhar aquilo que se aparenta coloca-se como condição de realização narcísica.

Dessa forma, a onipresença da mídia produz uma avalanche de imagens que termina por sufocar a possibilidade criativa do sujeito desejante desenhar uma estética para suas experiências vividas, ou seja, impede que ele inscreva o próprio desenho de si, sem utilizar-se das imagens já desenhadas pelo outro (VILHENA; MEDEIROS; NOVAES, 2005). O corpo, na contemporaneidade, é o protagonista na espetacularização da vida cotidiana, cuja presença marca um status de capital. Esse corpo agora é posto como algo disponível para ser alterado e esculpido, no qual cada sujeito é responsável pela sua construção e ainda tem que lidar com todas as demandas sociais, numa dialética tensa entre exigências de cunho social e individual.

Agora visto como obra de arte, o corpo é teatralizado, ou melhor, é o palco onde as palavras são encenadas. Em um mundo povoado pelos murais e outdoors, uma nova forma de escrita se estabelece. Os signos condensados na figura do corpo referenciam os valores culturais da sociedade do consumo: jovialidade, beleza, aparência de felicidade e poder de atração sexual.

O corpo agora recebe estatuto ativo na construção de identidades, ou seja, uma nova configuração. É sobre esse material bruto do corpo que a sociedade cogita sua constituição da subjetividade, pois ele serve de suporte memorial para inscrições biográficas e valorativas de todos os tempos. Em um contexto em que a sociedade é marcada pelo excesso de imagens e escassez de palavras, as práticas de marcação corporal, tão frequentes na atualidade, além de apontar para uma crise na capacidade de representação, servem também como estratégia no auxílio dessa inscrição no psíquico (VILHENA; ROSA; NOVAES, 2015).

Um exemplo pode ser expresso na adesão que a sociedade faz às rotinas de exercícios físicos exaustivos, acompanhados por uma severa dieta alimentar. Isso mostra uma marcação

\section{POLÊM!CA $\mid$ LABORE}

Polêmica - Revista Eletrônica da Uerj - Rua São Francisco Xavier, 524, $1^{\circ}$ andar bloco D, sl.1001 • Tels.: +55 21 2334-4088 / 4087 • http://www.e-publicacoes.uerj.br/index.php/polemica/index http://www.labore.uerj.br • laboreuerj@yahoo.com.br 
corporal que ajuda na ressignificação do olhar social, que até um certo período patologizava e marginalizava tal sujeito. Crescentemente, a rotina do fitness, aliada a uma dieta sem flexibilizações, vem permitindo que um número cada vez maior de pessoas narre a substituição do sentimento de exclusão por um lugar de destaque e prestígio (NOVAES, 2013).

Colocar ênfase aos procedimentos de cuidado do corpo está relacionado a esses novos processos de subjetivação, característicos da contemporaneidade. O corpo funciona como superfície em que o mundo interno e externo imprime seus conflitos; as marcas podem ser fixadas na pele física, desenhadas, ou receber contornos torneados com um conjunto de representações que têm a capacidade de barrar os excessos de fora ou de dentro do sujeito, como uma espécie de fechamento do buraco simbólico que constitui os sujeitos (VILHENA; ROSA; NOVAES, 2015).

Essa constante busca pelo corpo ideal, trabalhado na performance e aparência bela, representa uma passagem ao ato, no qual, o agir no corpo se tornou um registro malsucedido no simbólico, pois significa um "simples gozo sintomático que segue, interrompendo-se na dor física, para gerar alívio da angústia" (VILHENA, ROSA; NOVAES, 2015, p. 142). Novaes e Vilhena (2015) apontam em seu texto para várias dessas realidades. Exemplos disso são as próteses e substâncias químicas quando plantadas ao corpo, as quais impõem uma metamorfose devota à superfície corporal, remexendo-o, esticando-o e remodelando-o, parecendo convocar o sujeito a reescrever, na pele, a própria história apagada.

Em uma época cuja comunicação em massa é instantânea, ou melhor, onde há uma transformação do trabalho cultural, das obras de pensamento e arte em entretenimento, a sociedade se transforma em espectadora. Segundo Vilhena, Medeiros e Novaes (2005), a cultura da mídia parece estar sempre afirmando, através de simulacros, que você pode! - e pode imediatamente. Todavia, o processo de constituição do sujeito não é marcado nem pelo instantâneo, nem pelo imediato - há um processo.

Tais discursos normatizantes do corpo, pouco a pouco, vão tomando conta da vida simbólica/subjetiva do sujeito. Nota-se que o sofrimento psíquico, que hoje chega à clínica, denota o fracasso de um ideal de realização que passa diretamente pelo viés da estética. Nesse ponto, vale a interrogação: existe clínica sem estética? Bem, levando-se em consideração que todo sujeito se encontra aferrado a uma estética do sofrimento em nome de uma idealização, poder-se-ia responder taxativamente: não (FIGUEIREDO, 2004).

\section{POLÊM!CA $\mid$ LABORE}

Polêmica - Revista Eletrônica da Uerj - Rua São Francisco Xavier, 524, $1^{\circ}$ andar bloco D, sl.1001 • Tels.: +55 21 2334-4088 / 4087 • http://www.e-publicacoes.uerj.br/index.php/polemica/index http://www.labore.uerj.br • laboreuerj@yahoo.com.br 
Dessa forma, considera-se uma pessoa, por exemplo, que está acima do peso como desleixada ou até mesmo preguiçosa, fixando-se, portanto, no imaginário social a figura da gordura associada à doença, enquanto que um anoréxico é visto com piedade. Há, portanto, uma balança de julgamento simbólica que define os sintomas aceitos socialmente e aqueles que devem ser crucificados. Uma pessoa que apresenta sintomas ansiosos é aceita pela sociedade devido a sua capacidade de produção efetiva, enquanto que os depressivos são levados a um diagnóstico psiquiátrico e, por consequente, à internação, pois ao contrário do ansioso, o depressivo paralisa, o que é inadmissível numa sociedade imediatista que cultua a performance acima de tudo.

É notório que muitos sofrem pela angústia de ter que se livrar do sofrimento instantaneamente, que é advindo da obrigação de enquadrar-se, muitas vezes, ao padrão hegemônico - belo, magro, eficiente, feliz e bem-sucedido. A cultura das sensações corporais preconiza a boa forma, a sensualidade, o estímulo da beleza e o consumo de drogas sintéticas que induzem o sujeito a um estado emocional eufórico e de êxtase (NOVAES; VILHENA, 2006).

Percebe-se uma mudança significativa na forma como as pessoas lidam com sua infelicidade cotidiana. Segundo Rita de Almeida, em uma entrevista com a jornalista e escritora Eliane Brum (2013), estamos nos tornando uma geração de humanos que temem sua própria humanidade, ou seja, a infelicidade se tornou uma "perda de tempo" para a geração atual. Portanto, a pressa talvez seja o sintoma mais evidente da contemporaneidade.

Novaes (2013) afirma que a ideia de que só se é feio quem quer e que o corpo sarado é acessível a todos é ilusória. Isso é o que faz pessoas adoecerem. Trata-se de um processo astuto e lento que vai se dando nos seios das relações sociais. Afinal, convencer o sujeito de que ele é o único responsável pelo seu corpo, é produzir um instrumento valioso e eficiente de regulação corporal. As chamadas doenças da beleza se tornaram, portanto, um sintoma social.

Eliane Brum (2016) traz considerações significativas a respeito da condição humana da época atual, a qual define com a expressão "exaustos-e-correndo". O corpo se tornou um estorvo, um incômodo, um não-dá-conta que adoece, fica ansioso e se deprime. É por isso que dopa-se o corpo, porque só dopado para continuar correndo, mesmo estando exausto. Por sermos a sociedade do desempenho, as leis agora são projetos, iniciativas, motivação e a excessiva positividade (EHRENBERG, 2010). A sociedade torna-se uma coletividade que

\section{POLÊM!CA | LABORE}

Polêmica - Revista Eletrônica da Uerj - Rua São Francisco Xavier, 524, $1^{\circ}$ andar bloco D, sl.1001 • Tels.: +55 21 2334-4088/4087 • http://www.e-publicacoes.uerj.br/index.php/polemica/index http://www.labore.uerj.br • laboreuerj@yahoo.com.br 
mede o grau de felicidade das pessoas pelo tanto de coisas, bens ou serviços que elas são capazes de consumir.

É notório que hoje há uma dificuldade de compreender que aquilo que se sente como sofrimento pode ter um significado e um motivo que precisa ser escutado. Todavia, em busca do alívio imediato, correm atrás de medicamentos. Dessa forma, o doping cumpre a função de censurar os protestos do mundo interno, o qual acabou por ficar a oceanos de nós. Na realidade, o uso correto e ético de medicamentos se dá quando leva a pessoa a falar, e não fazê-lo calar. Muitas pessoas, além de sofrer pelo motivo que as levou a procurar ajuda, sofrem ainda mais pela angústia de ter que se livrar daquele sofrimento rapidamente, a qualquer custo.

Freud (1930), em seu livro O mal-estar na civilização, apresenta variadas reflexões acerca do papel da cultura em relação ao sofrimento, bem como possíveis caminhos criativos para evitá-lo, como, por exemplo, quando há sublimações das pulsões mediante as artes. No entanto, considerações importantes são feitas no sentido de mostrar que o homem deseja uma felicidade plena, uma vida sem dor e desprazer. Todavia, existem normas civilizatórias capazes de inibir aquilo que o autor denominou de libido. Assim, ainda que haja essa aspiração à felicidade - uma meta constante de evitar o desprazer - há limitações constitucionais.

A argumentação expressa até o momento acerca das formas de instrumentalização do corpo e do predomínio do imaginário fundamentam, justamente, a nossa preocupação científica por pesquisar as representações sociais ligadas ao esporte na contemporaneidade, dado que o fenômeno esportivo, por ser uma manifestação da e na cultura, acaba sendo contaminado por esses matizes contextuais. A premissa de base é que, por diversos processos sociopolíticos, econômicos e subjetivos, se tem gerado um empobrecimento simbólico na prática esportiva, tanto no microespaço social das pessoas comuns, quanto no âmbito global das figuras reconhecidas. O desafio aqui é propor algumas reflexões críticas e, eventualmente, provocar desconstruções de valor subjetivo e ético para o campo das ciências sociais, humanas e esportivas.

\section{O desvanecimento subjetivo na prática esportiva: uma contemporaneidade do excesso}

Neste estudo, o esporte é concebido a partir da perspectiva do modelo analítico de Wanderley Marchi Junior, que o compreende como:

\section{POLÊM!CA $\mid$ LABORE}


[...] um fenômeno processual físico, social, econômico e cultural, construído dinâmica e historicamente, presente na maioria dos povos e culturas intercontinentais, independentemente da nacionalidade, língua, cor, credo, posição social, gênero ou idade, e que na contemporaneidade tem se popularizado globalmente e redimensionado seu sentido pelas lógicas contextuais dos processos de mercantilização, profissionalização e espetacularização (MARCHI JUNIOR, 2015, p. 59).

Assim, justamente por ser um fenômeno social atravessado por valores e tradições, assistimos ao longo das últimas décadas o crescimento do esporte (notadamente de alto rendimento) como gerador de renda e riqueza. Como resultado de tal expansão (ou talvez até mesmo como uma das causas dela) testemunhamos a chegada de diversos elementos empresariais na administração das organizações esportivas tais como os próprios empresários e clientes, aliado ao incremento de valores como eficiência, resultado e competitividade. (GONÇALVES; CARVALHO, 2006).

Destarte, o esporte hoje é tido como uma indústria capaz de envolver variadas organizações, sejam públicas, não lucrativas, privadas e, de maneira especial, empresas de entretenimento, como a mídia televisiva. O futebol foi transformado numa indústria que movimenta milhares de sujeitos no mundo todo. A mercantilização, nesse caso, ocorre por intermédio da

venda de direitos de uso da marca de seleções e clubes ou da imagem de jogadores para empresas, ou da venda dos direitos de transmissão de jogos por televisão, rádio e Internet, sem contar as transferências de jogadores entre clubes e entre países, tudo isso, somado, superou em muito a antiga fonte de recursos que era a renda obtida com a venda de ingressos nos estádios (GONÇALVES; CARVALHO, 2006, p. 24).

Dessa forma, tem-se início tanto a produção dos espetáculos esportivos como a criação dos denominados mitos, os atletas profissionais, que também são submetidos a essa lógica de mercado. Para Ehrenberg (2010), os esportistas agora estão inclinados a adotar um modo de ação empresarial para administrar suas imagens, abandonando assim o contexto restrito das práticas esportivas ao seguir essa postura de sistema de condutas de si que consiste em implicar o indivíduo na sua autonomia e responsabilidade. Dessa forma, o esporte é assumido como estilo de vida dessubjetivado, pleno de imperativos capitalistas e não apenas um exercício físico; é um estado de espírito e não uma pedagogia virtuosa do corpo.

O esporte, ao ficar inserido na lógica da espetacularização da vida cotidiana, especialmente a partir de registros como corpo, saúde e visibilidade performática, tributa para um ideal de excelência que declina os derrotados e glorifica os vencedores. Nesta trama

\section{POLÊM!CA $\mid$ LABORE}

Polêmica - Revista Eletrônica da Uerj - Rua São Francisco Xavier, 524, $1^{\circ}$ andar bloco D, sl.1001 • Tels.: +55 21 2334-4088 / 4087 • http://www.e-publicacoes.uerj.br/index.php/polemica/index http://www.labore.uerj.br • laboreuerj@yahoo.com.br 
tanatopolítica (AGAMBEN, 2007), se expressa uma desvalorização da experiência singular do esportista e uma supervalorização do desempenho fisiológico, sem importar os desdobramentos físicos e subjetivos que sejam produzidos nessa busca por cumprir ideais. Esse tanatopoder não emana de uma instituição oficial ou de uma figura formalmente reconhecida da cultura. É um poder silencioso, imaginário e consentido pelos indivíduos e pelas massas psicológicas (FREUD, 1966), condição que o faz mais efetivo e perigoso.

O esporte atualmente promove a imagem de um sujeito autônomo, que produz sua saúde e aparência física como um empreendedor de sua própria existência (EHRENBERG, 2010). Segundo Vilhena, Medeiros e Novaes (2005), esse controle da feição traduz-se não somente na atribuição de características estéticas, mas as acometem de julgamentos morais e significados sociais. Assim, o singular de cada sujeito e o sentido que ele atribui a esse fenômeno muitas vezes escapa ou some.

Já quando se trata da questão do corpo como palco dos processos de (des)subjetivação é importante pontuar o crescimento do fenômeno cuja presença se tornou tendência na época atual: a medicalização da vida. É uma problemática que perpassa a vida do sujeito na contemporaneidade como, por exemplo, a vida de atletas de alto rendimento e praticantes de esporte, com práticas do doping ou qualquer outra substância que auxilie na potencialização de suas performances. A farmacologia abriu portas e os convida a adentrar, ecoando: "Venham! A vida fica mais fácil aqui”.

É claro que essas práticas não se restringem somente aos praticantes de modalidades esportivas, mas a todos aqueles que se utilizam de medicamentos para "aprimorar" o seu desempenho (laboral, sexual e escolar). Aqui podemos falar do conceito de "melhor do que bem", tratado pelo sociólogo francês Ehrenberg em sua obra $O$ culto da performance. Uma concepção de que tudo que já está bom, funcional ou adequado pode "ganhar um up" com a ajuda de remédios (EHRENBERG, 2010).

No esporte, isso é muito frequente, principalmente, nas vivências dos atletas de alto rendimento. Isso porque existe toda uma pressão social visando à superação de limites físicos e mentais, como ao esconder um quadro de dor, considerado um sinal de fraqueza. Tudo isso ocorre, portanto, devido a essa cultura atlética, que envolve não apenas o atleta, mas técnicos, professores, fãs, colegas de time e, especialmente, o mercado esportivo que recompensa somente desempenhos excelentes e vitórias (SILVA; RABELO; RUBIO, 2010).

\section{POLÊM!CA $\mid$ LABORE}

Polêmica - Revista Eletrônica da Uerj - Rua São Francisco Xavier, 524, $1^{\circ}$ andar bloco D, sl.1001 • Tels.: +55 21 2334-4088 / 4087 • http://www.e-publicacoes.uerj.br/index.php/polemica/index http://www.labore.uerj.br • laboreuerj@yahoo.com.br 


\section{Método}

Trata-se de uma pesquisa de natureza qualitativa (GONZÁLEZ REY; PATINO, 2017; GONZÁLEZ REY, 1997, 2000), visto que a compreensão da proposta a ser pesquisada não pode ser mensurável na perspectiva empírico-analítica, pois a realidade e o sujeito acabam por ser tornarem elementos indissociáveis. Assim sendo, ao abordar o sujeito na pesquisa, leva-se em consideração suas produções subjetivas, suas particularidades e singularidades, as quais nem sempre são passíveis de serem traduzidos em números quantificáveis (CHIZZOTTI, 2009).

De acordo com esta perspectiva qualitativa assumida (GONZÁLEZ REY, 1997, 2000; GONZÁLEZ REY; MITJÁNS MARTÍNEZ, 2017), se consideraram três princípios epistemológicos orientadores no estudo: 1) a singularidade como fonte legítima de produção de conhecimento; 2) a dialogicidade dentro do trabalho de campo, o que implicou desenvolver um mútuo engajamento subjetivo entre pesquisadores e participantes; e 3) um caráter construtivo interpretativo na construção das informações, o qual possibilitou novas zonas de inteligibilidade sobre o fenômeno.

Participaram da pesquisa duas turmas do terceiro ano regular do turno matutino de um Colégio Estadual da cidade de Miracema, do Tocantins. Os Termos de Consentimento Livre e Esclarecido (TCLE) foram assinados pelos adolescentes, ou quando necessário, pelos pais ou representante legal para se obter a autorização da participação. A pesquisa foi submetida e aprovada pelo comitê de Ética da Plataforma Brasil.

Como estratégia metodológica para o levantamento das informações, foram realizados dois grupos focais com duração em torno de 50 minutos, sob a condução de 6 coordenadores. Participaram, ao todo, 27 estudantes secundaristas. Grupos focais, também chamados de entrevistas focalizadas em grupo, têm sido uma técnica de natureza qualitativa para um número expressivo de pesquisas, caracterizando-se pela finalidade primordial de buscar compreender a construção das percepções e representações sociais em determinados contextos (ESCOBAR; BONILLA-JIMÉNEZ, 2011; BECK; BRYMAN; FUTING, 2004; LERVOLINO; PELICIONI, 2001).

Os temas norteadores para discussão foram: competição, mercantilização e lazer. Assim, foram utilizadas uma imagem e duas situações que envolviam a prática esportiva como disparadores. Na tentativa de construir informações a respeito do primeiro eixo, foram

\section{POLÊM!CA $\mid$ LABORE}

Polêmica - Revista Eletrônica da Uerj - Rua São Francisco Xavier, 524, $1^{\circ}$ andar bloco D, sl.1001 • Tels.: +55 21 2334-4088 / 4087 • http://www.e-publicacoes.uerj.br/index.php/polemica/index http://www.labore.uerj.br • laboreuerj@yahoo.com.br 
mostrados alguns comentários de uma notícia publicada pelo Globo Esporte ${ }^{1}$ acerca da queda do atleta Diego Hypólito, que resultou na perda da oportunidade de disputar a final na ginástica artística masculina, pelas Olimpíadas 2012.

Já com o objetivo de discutir a mercantilização do esporte, foi exibida aos participantes da pesquisa uma imagem que abarcava tanto a temática do corpo, esporte e profissionalização, como também variadas marcas esportivas frequentemente mostradas pelos veículos de comunicação. Por último, visando discussões sobre lazer, foram feitas associações aos temas já discutidos a fim de abrir espaço para esta temática.

Dessa forma, as representações sociais que se construíram teoricamente a partir da análise do discurso dos estudantes secundaristas - os sujeitos-alvos no processo de compreensão do objeto de pesquisa - foram acerca da espetacularização da vida cotidiana circunscrita no corpo, na saúde e na visibilidade performática dos atletas de alto rendimento e praticantes de esporte.

A Teoria das Representações Sociais (MOSCOVICI, 2000; JODELET, 2005) propõe que não se pode conhecer sem estabelecer relação entre o tema/objeto e o seu contexto, ou seja, não há separação entre o sujeito social e o seu saber concreto da realidade a qual pertence e se constitui, assim como a construção desse saber não pode se desvincular da subjetividade (GONZÁLEZ REY, 2008; ARRUDA, 2002). Por estar intimamente ligada com a subjetividade, a representação social não só se constitui como uma produção simbólica, pois em realidade ela está mediada, principalmente, por processos emocionais não conscientes que são gerados pelas pessoas e grupos. Nessa trama simbólico-emocional da representação social (GONZÁLEZ REY, 2008), elas usualmente escapam ao raciocínio consciente e se expressam, de forma eloquente, em práticas culturais, discursos implícitos e omissões linguísticas.

De acordo com Sá (1998), os fenômenos de representação social estão espalhados na cultura, nas instituições, nas práticas sociais, nas comunicações interpessoais e nos pensamentos individuais. Assim, os objetos de pesquisa que se constroem a partir das representações sociais são menos complexos que o próprio fenômeno. É a partir desse olhar metodológico que o presente trabalho se desenvolveu.

\footnotetext{
${ }^{1}$ Programa de TV brasileiro de conteúdo esportivo.

\section{POLÊM!CA $\mid$ LABORE}

Polêmica - Revista Eletrônica da Uerj - Rua São Francisco Xavier, 524, $1^{\circ}$ andar bloco D, sl.1001 • Tels.: +55 21 2334-4088 / 4087 • http://www.e-publicacoes.uerj.br/index.php/polemica/index http://www.labore.uerj.br • laboreuerj@yahoo.com.br
} 


\section{Resultados e interpretações}

A partir dos resultados construídos, emergiram quatro categorias de análise: Visibilidade, Padrão de Beleza, Desvalorização do Atleta e Saúde.

A categoria Visibilidade tratou de uma dimensão do esporte enquanto espetáculo, mais especificamente a visão de mundo imposta pela mídia, que dissemina uma cultura ilusória na tentativa de melhorias econômicas. A tensa relação entre a mídia e os indivíduos se aprecia em alguma das reflexões dos participantes:

[...] Talvez a mídia que, na verdade, tem muita influência. A mídia faz o que quiser com as pessoas, nós somos fixados, nós somos atraídos como se fossemos zumbis, pela mídia. (Participante do Grupo Focal).

Segundo Leite (2008), existe uma cultura esportiva aliada ao capitalismo que mantém a mídia enquanto alicerce, tendo como objetivo propagar para a sociedade um caráter prazeroso e sem esforço do esporte, atendendo aos interesses econômicos e sociais e não mais uma promoção da saúde e bem-estar. Dessa forma, exacerbar a experimentação real do mundo, a partir de figuras imaginárias, revela, dentre outros aspectos, o caráter espetacularizado da vida cotidiana.

Quando a vida cotidiana passa a se submeter ao jogo de espetáculos, a mídia se coloca como o palco desse exibicionismo. É possível analisar, segundo as falas dos participantes, que a mídia é detentora de muita influência, e utiliza-se de tal influência para atrair as pessoas para aquilo que ela propõe: degradação do "ser" em "ter". O investimento da mídia está na aparência, no ser fitness e magro, o que, surpreendentemente, se torna sinônimo de saúde. Uma avalanche de imagens é produzida terminando por sufocar a possibilidade criativa do sujeito desejante desenhar uma estética para suas experiências vividas.

Assim, o corpo é posto como algo disponível para ser alterado e esculpido, em que cada sujeito é individualmente responsável pela sua construção, e a mídia se torna parceira e juíza tirana nesse processo, no qual ao estereotipar a sociedade, ela define o corpo que as pessoas devem ter:

Isso já é uma influência que a mídia colocou na cabeça das pessoas. Todos devem ter o corpo perfeito, o corpo padrão. Por isso que depois disso surgiu essa ideia de que a sociedade deve ter o corpo perfeito, ficam o tempo todo se comparando e se queixando do seu próprio corpo, se cobrando pelo um ideal de corpo. Se perguntando a si mesmo: será que eu sou feliz com esse corpo? Isso porque a sociedade se influencia por conta da mídia. (Participante do Grupo Focal).

\section{POLÊM!CA $\mid$ LABORE}

Polêmica - Revista Eletrônica da Uerj - Rua São Francisco Xavier, 524, $1^{\circ}$ andar bloco D, sl.1001 • Tels.: +55 21 2334-4088 / 4087 • http://www.e-publicacoes.uerj.br/index.php/polemica/index http://www.labore.uerj.br • laboreuerj@yahoo.com.br 
Nesta tirania midiática do contemporâneo, a categoria Padrão de Beleza surgiu com um marcador social de gênero, em que homens e mulheres são atravessados cotidianamente por diferentes estéticas ditadas por uma sociedade do consumo.

Se a gente for pensar, a mulher se importa mais, a sociedade exige mais da mulher. A gente vê mais mulheres nas propagandas. É a mulher que mostra para outra mulher que ela é mais. O homem não está nem aí para os outros homens. É difícil ver um homem querendo emagrecer; as mulheres pensam como os homens verão elas. (Participante do Grupo Focal).

De fato, como assinala Louro (1997), existe um grande investimento nos corpos, seja nas imposições culturais, de saúde, beleza, e ainda as exigências estéticas, morais, higiênicas, dentre outras. Tudo isso acontece com uma ênfase significativa de gênero, especialmente, em relação aos cuidados físicos, exercícios e adornos. Os comportamentos e gestos tornam-se, então, responsáveis pelas classificações e decodificações de marcas que se expressam a partir das apresentações corporais. Dessa forma, a mulher se torna mercadoria constantemente inacabada, julgada e empobrecida subjetivamente, com a qual se obstaculizam subjetivações alternativas e contraculturais.

No mundo contemporâneo, mergulhado em imagens, existe muito mais a exibição de mulheres do que de homens, como forma de reforçar seus arquétipos, aparentando estimular a ideia de colocar em imagens o objeto de desejo. Nesse caso, a imagem de mulher se justapõe com a de beleza e, como segundo desfecho, à de saúde e juventude. Tais imagens que representam o corpo feminino refletem corpos ultra trabalhados, sexuados e cujo intuito está em responder sempre ao desejo do outro (VILHENA; MEDEIROS; NOVAES, 2005).

Pode-se afirmar que o entrelaçamento entre o vocabulário beleza e tudo que diz respeito à feminilidade demostra ser tão antigo quanto a civilização. Por exemplo, na abordagem da consciência mítica, a disputa contada em A Ilíada, de Homero, pela cidade mais importante no mundo grego arcaico, Tróia, foi um confronto entre três deusas e uma mortal, em torno da beleza.

$\mathrm{Na}$ tradição judaico-cristã, atribui-se à mulher os males do mundo ao marcar Eva como aquela que cedeu às tentações do corpo, seduziu Adão e provocou a expulsão do paraíso. Dessa forma, durante a Idade Média, a figura da mulher é vista como armadilha do pecado, uma tentação do diabo, na qual a beleza das mulheres seria um encobrimento enganoso de uma essência impura.

\section{POLÊM!CA $\mid$ LABORE}

Polêmica - Revista Eletrônica da Uerj - Rua São Francisco Xavier, 524, $1^{\circ}$ andar bloco D, sl.1001 • Tels.: +55 21 2334-4088 / 4087 • http://www.e-publicacoes.uerj.br/index.php/polemica/index http://www.labore.uerj.br • laboreuerj@yahoo.com.br 
$\mathrm{Na}$ Renascença, as representações do feminino são admitidas, desde que despojada de sua sensualidade maligna ou desde que como um efêmero detalhe. A partir da publicação de Émile ou De L'éducation, Rousseau estabelece um outro paradigma: a virtude do amor materno como ideal de feminilidade. O recato, a doçura, a fragilidade e a submissão serão as características da mulher enaltecidas pela Modernidade. Com a preponderância da visão no que diz respeito à representação corporal, constrói-se um aspecto fundamental para mulher no contemporâneo (VILHENA; MEDEIROS; NOVAES, 2005).

A discussão acerca do marcador de gênero é bastante ampla e pode ser pensada por meio de representações normativas de feminilidade e masculinidades, as quais designam aquilo que é correto, natural e valorizado, levando em consideração a diferença do sexo biológico. No esporte isso é muito comum, seja na escolha de atividades esportivas ou mesmo no maior ou menor envolvimento em atividades físicas ou de lazer.

Por exemplo, mulheres praticam muito mais caminhada, ginástica, balé clássico, ginástica rítmica ou quaisquer outras atividades que expressem delicadeza e graciosidade; enquanto homens se envolvem em modalidades esportivas de grande intensidade e choque físico, que demandam força e esforços físicos, e geralmente de caráter competitivo (BRASIL, 2016).

Os exemplos aqui citados servem para trazer à tona discursos e práticas instituídas, que exercem uma pedagogia de gênero expressas a partir dos corpos, moldados pela cultura. Além disso,

Tem uma questão de preconceito, tipo, passa uma mulher do corpão e bonitona na rua todo mundo olha, depois passa uma gordona para ver, já observa a diferença. Agora para a mulherada tem aqueles homens musculosos, depois passa um com os braços bem fininhos, quando o cara estiver velho aquilo ali vai murchar... isso é superficial. (Participante do Grupo Focal).

Segundo Novaes e Vilhena (2006), existe uma angústia advinda da obrigação de enquadrar-se, muitas vezes, ao padrão hegemônico da mulher - bela, magra, eficiente, feliz e bem-sucedida. A cultura das sensações corporais preconiza a boa forma, a sensualidade, o estímulo da beleza e o consumo de drogas sintéticas que induzem o sujeito a um estado emocional eufórico e de êxtase. Certamente, a contemporaneidade caracteriza-se por vários excessos, principalmente, o da imaginarização tanática da ontologia.

\section{POLÊM!CA $\mid$ LABORE}

Polêmica - Revista Eletrônica da Uerj - Rua São Francisco Xavier, 524, $1^{\circ}$ andar bloco D, sl.1001 • Tels.: +55 21 2334-4088 / 4087 • http://www.e-publicacoes.uerj.br/index.php/polemica/index http://www.labore.uerj.br • laboreuerj@yahoo.com.br 
Brum (2018), em seu texto $O$ ataque dos machos brancos, expressa muito bem aspectos ligados a esse marcador social de gênero, especialmente, uma crítica a essa ideia de que o corpo da mulher pode ser tido como um capital, um território público, cujo direito de assediar, avaliar e ofender é adquirido. E, como se não bastasse, existem posicionamentos e agressões expressas publicamente acerca do corpo da mulher; este somente deve ser mostrado na condição de estar sob um determinado padrão de beleza.

$\mathrm{Na}$ categoria Desvalorização do atleta, apareceram aspectos relacionados à falta de investimento nas crianças e jovens em relação ao esporte, acontecendo isso apenas quando existe um considerável rendimento do atleta. Novamente, a mídia exerceria somente o papel de mostrar e idolatrar aqueles que conseguem obter sucesso mediante as modalidades esportivas, dando a eles certa visibilidade:

No Brasil, o atleta só é valorizado quando ele está bombando/arrasando, explodindo. Acredito que há uma desvalorização do atleta, é um erro valorizar o atleta apenas quando ele tem uma idade elevada, sendo que deveria se iniciar um trabalho ainda jovem para aproveitar ainda mais do atleta. (Participante do Grupo Focal).

Sobre isso, Capraro (2011, p. 170) aponta que os “atletas-heróis são personagens criados e sustentados pela mídia, que através da projeção em anúncios publicitários, sustentam a venda de produtos e movimentam o mercado". Logo, é possível analisar que, assim como o esporte consome a sociedade, a sociedade consome o esporte em um sentido de mão-dupla, no qual os atletas se veem atravessados pelo olhar minucioso sobre a aparência, regulamentando diferenças e padrões estéticos em termos daquilo que é adequado ou não e que, por consequente, mantém as engrenagens do mercado funcionando. Agora, uma vez cumprido seu papel produtivista, os atletas se tornam objetos descartáveis, desubjetivados e sem lugar dentro da cultura tirana do espetáculo:

Um time todo, uma só pessoa se sobressai. A mídia coloca um único lá em cima, por quê? Na questão da competição as pessoas se sentem desanimadas porque não são vistas, não dão importância para o seu trabalho. Por isso muitos desistem. (Participante do Grupo Focal).

Já na categoria Saúde, ficou evidente que ser saudável está atrelado a um corpo fitness, à ideia de um corpo perfeito, espetacularizado. Para isso, segundo relatos, aumenta-se o uso de substâncias como anabolizantes e suplementos:

\section{POLÊM!CA $\mid$ LABORE}

Polêmica - Revista Eletrônica da Uerj - Rua São Francisco Xavier, 524, $1^{\circ}$ andar bloco D, sl.1001 • Tels.: +55 21 2334-4088/4087 • http://www.e-publicacoes.uerj.br/index.php/polemica/index http://www.labore.uerj.br • laboreuerj@yahoo.com.br 
Eu acho que a mídia está investindo muito em uma geração fitness, onde a moda tem que ser saudável. Não que seja ruim praticar esporte, isso é ótimo para as pessoas terem saúde, evita problemas futuros. Mas, a mídia investe muito nisso, para as pessoas que são gordinhas, que não se sentem bem em ver uma pessoa magrinha que tem um corpo perfeito sem esforço, a mídia entra com produtos que prometem emagrecer do dia para a noite, com cirurgias. A pessoa não tem dinheiro. Leva a pessoa a ficar com isso na mente, desejando ser magra. A sociedade exige que seja magra, deve-se ter um corpo/imagem perfeita. A mídia estereotipa a sociedade; ela define o corpo que a sociedade tem que ter. Ela não preza saúde. Ela só se importa com o corpo que a pessoa tem, se não ela não investiria tanto em medicamentos que prejudicam a saúde. (Participante do Grupo Focal).

Parece que para ter saúde, hoje, é preciso primeiramente perder a si mesmo e assim encontrar qualquer alívio para a inflexibilidade da finitude do sujeito, pois o que se precisa é adiar o desfecho trágico da existência humana, graças aos avanços da ciência farmacológica, cirúrgica e biotecnológica que inspiram uma falsa esperança do ser. É isso o que se chama aqui de tanatopolítica da contemporaneidade: silenciosa, desinstitucionalizada e sumamente voraz com os indivíduos.

Poderíamos dizer que, diante do medo das imperfeições inerentes à vida humana, é estabelecido um padrão de ser e de existir como sendo adequado e aceitável socialmente, esquecendo-se que, ao tentar fabricar uma humanidade infinita e esculpida com peças ditas perfeitas, forja-se uma figura monstruosa, pois o monstro é criado na confusão e horrores internos aos humanos. Tal configuração fornece um aparato externo corporificado do estado interno, em conflito com o mundo, e intensa pressão advinda dos medos que apavoram suas mentes. Assim como afirma Barboza (2017), “falar dos monstros é falar da nossa própria natureza" (p. 148).

No romance: ou o moderno Prometeu, de Mary Shelley, é notório como a criatura foi de todas as formas prejudicada por aquele que deveria lhe guiar no mundo - seu criador. É um monstro dotado de humanidade, inteligência, bondade, afeição, que busca, dentre outras coisas, entender a rejeição de todos ao seu redor, causada por sua aparência, e fazer parte da sociedade, na qual está inserida, como igual. Todavia, ela é vista como ser repelente, quando na verdade é a sociedade que age como tal.

Dessa forma, ao tentar conhecer a si mesmo, Frankenstein se transforma em um ser vingativo devido às circunstâncias que a cercam, estas sim, verdadeiramente monstruosas. A obra retrata a discussão de como a rejeição, o prejulgamento, a falta de sensibilidade do homem podem ser o verdadeiro horror que assola uma sociedade. A história do Criador e sua Criatura incomoda e horroriza por pertencer a um nível psicológico e não sobrenatural (SOARES, 2015).

\section{POLÊM!CA $\mid$ LABORE}

Polêmica - Revista Eletrônica da Uerj - Rua São Francisco Xavier, 524, $1^{\circ}$ andar bloco D, sl.1001 • Tels.: +55 21 2334-4088/4087 • http://www.e-publicacoes.uerj.br/index.php/polemica/index http://www.labore.uerj.br • laboreuerj@yahoo.com.br 
O monstro de Mary Shelley é um ser sem identidade, sem espécie, abandonado no mundo, privado de afeição e condenado a nunca fazer parte da sociedade que vive da aparência, da riqueza e do mérito do nome. O monstro de Frankenstein seria o sujeito que, hoje, não está enquadrado nos padrões de beleza impostos pela sociedade, essa que o formou, mas o repele. É nessa metáfora que o corpo idealizado e dito saudável está posto.

Foi possível observar, também, a contradição em relação aos veículos de comunicação, quando impõem um padrão de beleza e todavia apresentam variadas propagandas de alimentos considerados prejudiciais para a saúde:

Tem a questão da alimentação. A mídia é divergente demais. Ela te impõe um padrão de magreza, beleza, mas depois passa um comercial com coisas que não são tão saudáveis para a saúde/alimentação. Isso é bem contraditório. (Participante do Grupo Focal).

O povo quer tipo nem gordinho e nem magrinho, tipo panicat, aquele corpo que passa na televisão. O povo tem que ter aquele corpinho para seduzir. (Participante do Grupo Focal)

Há, ainda, uma balança contraditória de julgamentos do que é adequado e do que é inadequado. Um exemplo se expressa na adesão a uma rotina de exercícios físicos exaustivos seguida de uma mercantilização de uma dieta nada saudável, o que revela enormes contrassensos nas demandas sociais realizadas para os sujeitos. Mais uma vez, a superfície corporal sendo remexida, esticada e modelada para alcançar o ideal, mas, como todo ideal, sua aquisição está impossibilitada.

No trecho anteriormente citado, podemos ver como o corpo denominado de gordo está atrelado ao imaginário social divulgado pela mídia - impregnado de estigmas e preconceitos por representar um caráter pejorativo de um corpo não saudável (SUDO et al., 2005). Já o corpo magro é visto como saudável, o que o torna valorizado e desejado por ser visto como símbolo da felicidade contemporânea. Por essa razão, o número de intervenções cirúrgicas, dietas e exercícios físicos se tornam frequentes para se alcançar este corpo ideal.

\section{Considerações finais}

A partir dos resultados desse trabalho, percebe-se que o sujeito, em cada contexto que o perpassa, se constitui nas peculiaridades de sua sociabilidade e na inscrição do memorial biográfico de seu tempo. Na contemporaneidade, é perceptível que os signos condensados na figura do corpo, acabam por fazer referência aos valores culturais de seu tempo, ou seja, à ilusão

\section{POLÊM!CA $\mid$ LABORE}

Polêmica - Revista Eletrônica da Uerj - Rua São Francisco Xavier, 524, $1^{\circ}$ andar bloco D, sl.1001 • Tels.: +55 21 2334-4088 / 4087 • http://www.e-publicacoes.uerj.br/index.php/polemica/index http://www.labore.uerj.br • laboreuerj@yahoo.com.br 
da infinitude humana. $\mathrm{O}$ corpo do atleta de alto rendimento e/ou praticante de esporte é posto e sujeitado como algo a ser teatralizado e tomado de maneira performática. Isso implica em um corpo marcado por um contexto mediado pelo excesso de imagens e um parcial esvaziamento das palavras. Dito de outra forma, as afetações corporais, na atualidade, apontam uma crise do sujeito de representação pela via da linguagem, ou seja, as palavras passaram a ser atuações materializadas no corpo. A mediação de sujeito para sujeito e, consequentemente, para si mesmo, determinada por imagens, acaba por impedir que ele inscreva o próprio desenho de si. O que lhe resta são partes/imagens de outros que não o são, mas que o validam como tal.

Os discursos normatizantes do corpo, pouco a pouco, vão tomando conta da vida simbólica/emocional do sujeito e a ditadura da beleza/magreza se torna um sintoma social, devido a um crescente número de pessoas que sofrem por causa de sua estética diante da demanda social. Ou seja, muitos sofrem pela angústia de ter que se livrar do sofrimento instantaneamente, sentimento advindo da obrigação de enquadrar-se, muitas vezes, ao padrão hegemônico - bela(o), magra(o), eficiente, feliz e bem-sucedida(o). Trata-se, então, de um sujeito cuja reflexividade está evaporada, diluída e recluída.

Em um mundo volátil e envolvido por uma insustentável leveza do ser, nada é concreto e duradouro, há sempre mudanças instantâneas: cabelo, corpo, estilo de vida. Exaustos, mas correndo, permanecem os sujeitos - o que inclui atletas de alto rendimento e/ou praticantes de esporte - na tentativa de serem o que o Outro espera que eles sejam e de ter que se enquadrar nos padrões impostos socialmente. Ao se deparar com aquilo que tanto desejava, o sujeito se angustia devido a não ser aquilo - dado que agora impõe-se socialmente outra imagem - e assim, na tentativa de acabar com o sofrimento, o doping (de atletas ou não) apresenta-se como uma possibilidade de censurar os protestos do mundo interno, levando-o aos oceanos de si mesmo.

Dessa forma, os resultados da pesquisa evidenciam que o esporte mostrado pela mídia está diretamente ligado a uma lógica do espetáculo e à ideia ilusória de que ser saudável está atrelado ao corpo denominado perfeito - fitness -, esse expresso por marcadores sociais de gênero, e somente possíveis de serem mostrados e exibidos, quando submetidos ao padrão de beleza hegemônico.

Acaba por se evidenciar, também, que no imaginário social partilhado somente deve haver investimento em relação ao esporte, quando esportistas já apresentam resultados

\section{POLÊM!CA | LABORE}

Polêmica - Revista Eletrônica da Uerj - Rua São Francisco Xavier, 524, $1^{\circ}$ andar bloco D, sl.1001 • Tels.: +55 21 2334-4088/4087 • http://www.e-publicacoes.uerj.br/index.php/polemica/index http://www.labore.uerj.br • laboreuerj@yahoo.com.br 
significativos para serem exibidos pelos veículos de comunicação, relevando mais uma vez a predominância o modelo derrota/vitória e o reforço da visibilidade performática dos corpos.

Por fim, pode-se reconhecer, em tudo isso, vidas vividas à sombra de imagens, como um simulacro tão característico da sociedade contemporânea. Há uma passividade e aceitação diante de determinados modos de vida como resultado de padrões de atitude e comportamento mediados por imagens, surgindo, então, uma espécie de sombreamento marcado por representações, ilusões, perda de autenticidade e até mesmo um sufocamento da possibilidade criativa do ser.

\section{Referências}

AGAMBEN, G. Homo sacer: o poder soberano e a vida nua. Belo Horizonte: UFMG, 2007.

ARRUDA, Angela. Teoria das representações sociais e teorias de gênero. Cadernos de Pesquisa, n. 117, p. 127$147,2002$.

BECK, Michael; BRYMAN, Alan; FUTING, Liao. The Sage Encyclopedia of Social Science Research Methods. New Delhi: SAGE Publications, 2004.

BRASIL. Ministério do Esporte. Diesporte: diagnóstico nacional do esporte. O perfil do sujeito praticante ou não de esportes e atividades físicas da população brasileira [Internet]. Brasília: Ministério do Esporte, 2016. 70 p. (Caderno 2). Disponível em: http://www.esporte.gov.br/diesporte/diesporte_revista_2016.pdf. Acesso em: 5 dez. 2018.

BRUM, Eliane. Permissão para ser infeliz. Cult Carioca. 2013. Disponível em:

https://www.cultcarioca.com.br/2013/06/eliane-brum-permissao-para-ser-infeliz.html. Acesso em: 30 mar. 2019.

. Exaustos-e-correndo-e-dopados. El País. Brasil. 4 jul. 2016. Disponível em:

https://brasil.elpais.com/brasil/2016/07/04/politica/1467642464_246482.html. Acesso em: 30 mar. 2019.

O ataque dos machos brancos. El País. Opinião. 21 nov. 2018. Disponível em:

https://brasil.elpais.com/brasil/2018/11/21/opinion/1542809746_443796.html. Acesso em: 30 mar. 2019.

BARBOZA, Rafael Santos. O monstro demasiadamente humano: o olhar da psicanálise sobre o desamparo.

Psicanálise \& Barroco em revista, v. 15, n. 01, 2017.

CAPRARO, André Mendes et al. A imagem do atleta: publicidade em ano de Copa do Mundo de Futebol (Alemanha - 2006). Rev. bras. educ. fís. Esporte, São Paulo, v. 25, n. 1, p. 163-171, mar. 2011.

CHIZZOTTI, A. Pesquisa em ciências humanas e sociais. São Paulo: Cortez, 2009.

DEBORD, Guy (1967). A sociedade do espetáculo. São Paulo: Contraponto Editora, 1997.

EHRENBERG, Alain. O culto da performance: da aventura empreendedora a depressão nervosa. Aparecida: Editora Ideias \& Letras, 2010.

ESCOBAR, Jazmine; BONILLA-JIMÉNEZ, Francy Ivonne. Grupos focales: una guía conceptual y metodológica. Cuadernos Hispanoamericanos de Psicología, v. 9, n. 1, p. 51-67, 2011.

\section{POLÊM!CA $\mid$ LABORE}

Polêmica - Revista Eletrônica da Uerj - Rua São Francisco Xavier, 524, $1^{\circ}$ andar bloco D, sl.1001 • Tels.: +55 21 2334-4088 / 4087 • http://www.e-publicacoes.uerj.br/index.php/polemica/index http://www.labore.uerj.br • laboreuerj@yahoo.com.br 
FIGUEIREDO, Henrique. Sujeito, sofrimento psíquico e contemporaneidade: uma posição. Revista mal-estar e subjetividade, v. IV, n. 2, p. 277-295, 2004.

FREUD, Sigmund (1930). O mal-estar na civilização. In:

Sigmund Freud. Rio de Janeiro: Imago, 1974. V. 21. p. 81-178.

Edição Brasileira das Obras Completas de

GLOBOESPORTE. Diego Hypólito sofre queda e está fora da final no solo dos Jogos de Londres. Globo Esporte. 28 jul. 2012. Disponível em: http://globoesporte.globo.com/olimpiadas/noticia/2012/07/diego-hypolitosofre-queda-no-solo-e-esta-fora-da-final-no-solo-em-londres.html. Acesso em: 5 nov. 2018.

GONZÁLEZ REY, Fernando Luis. Epistemología cualitativa y subjetividad. São Paulo: Educ, 1997.

Investigación cualitativa en psicología: rumbos y desafíos. México: Paraninfo, 2000.

Subjetividad social, sujeto y representaciones sociales. Diversitas, v. 4, n. 2, p. 225-243, dez. 2008.

GONZÁLEZ REY, Fernando Luis; PATIÑO, José Fernando. La Epistemología Cualitativa y el estudio de la subjetividad en una perspectiva cultural-histórica. Conversación con Fernando González Rey. Estudios Sociales, v. 60, 120-127, 2017. DOI: https://dx.doi.org/10.7440/res60.2017.10.

GONZÁLEZ REY, Fernando Luis; MITJÁNS MARTÍNEZ, Albertina. Subjetividade. Teoria, epistemología e método. Brasília: Alínea, 2017.

GONÇALVES, Júlio Cesar de Santana; CARVALHO, Cristina Amélia. A mercantilização do futebol brasileiro: instrumentos, avanços e resistências. Cad. EBAPE.BR, Rio de Janeiro, v. 4, n. 2, p. 01-27, jun. 2006.

JODELET. Denise. Loucuras e representações sociais. Petrópolis: VOZES, 2005.

MARCHI JUNIOR, W. O esporte "em cena": perspectivas históricas e interpretações conceituais para a construção de um modelo analítico. Alesde, Curitiba, v. 5, n. 1, p. 46-67, 2015.

LEITE, W. S. S. Ilusão em Massa: O Papel da Mídia no Esporte. Lecturas Educación Física y Deportes (Buenos Aires), v. 123, p. -, 2008.

LERVOLINO, S. A.; PELICIONI, M. C. F. A utilização do grupo focal como metodologia qualitativa na promoção da saúde. Rev Esc Enf USP, v. 35, n. 2, p. 115-21, jun. 2001.

LOURO, Guacira Lopes. A emergência do "gênero". In: perspectiva pós-estruturalista. Petrópolis: Vozes, 1997. p. 14-36.

MOSCOVICI, Serge. The History and Actuality of Social Representations. In: DUVEEN, G. (org). Social Representations. Explorations in Social Psychology (120-155). Cambridge: Polity Press, 2000.

NOVAES, Joana. Ditadura da beleza: o corpo de classe. Ideias em Revista, ano V, n. 39, 2013.

NOVAES, Joana Vilhena; VILHENA, Junia. Meu corpo, minha prisão: em busca do corpo ideal. In: Congresso Internacional de Psicopatologia Fundamental, II, 2006, Belém. Anais. Set. 2006.

Corpo corpo meu. Existe alguém mais imperfeito do que eu? Ricerca in Psicoterapia, 5, p. 16-22, 2015. Disponível em:

http://www.researchgate.net/publication/282862713_Corpo_corpo_meu_Existe_alguem_mais_imperfeito_do_qu e_eu. Acesso em: $11 \mathrm{dez} .2018$.

SÁ, Celso Pereira de. A Construção do objeto de pesquisa em representações sociais. Rio de Janeiro: EdUERJ, 1998.

\section{POLÊM!CA $\mid$ LABORE}

Polêmica - Revista Eletrônica da Uerj - Rua São Francisco Xavier, 524, $1^{\circ}$ andar bloco D, sl.1001 • Tels.: +55 21 2334-4088 / 4087 • http://www.e-publicacoes.uerj.br/index.php/polemica/index http://www.labore.uerj.br • laboreuerj@yahoo.com.br 
SHELLEY, Mary. Frankenstein ou o moderno prometeu. Trad. Adriana Lisboa. 2. ed. Rio de Janeiro: Nova Fronteira, 2014.

SILVA, Elisa Martins da; RABELO, Ivan; RUBIO, Katia. A dor entre atletas de alto rendimento. Rev. bras. psicol. esporte, São Paulo, v. 3, n. 1, p. 79-97, jun. 2010.

SOARES, Janile Pequeno. Frankenstein e a monstruosidade das intenções: a criatura como representação da condição feminina. João Pessoa, 2015.

SUDO, I.; SUDO, N.; VASCONCELOS, N. A. de. Um Peso na Alma: Corpo gordo e Mídia. Revista Mal-estar e Subjetividade, v. 4, p. 65-93, 2005.

VILHENA, Junia de; MEDEIROS, Sergio; NOVAES, Joana de Vilhena. A violência da imagem: estética, feminino e contemporaneidade. Fortaleza: Revista Mal-Estar e Subjetividade, v. 5, n. 1, p. 109-144, 2005.

VILHENA, Junia; ROSA, Carlos Mendes; NOVAES, Joana de Vilhena. Narrando dores: a tatuagem como narrativa. Cad. Psicanál. - CPRJ, Rio de Janeiro, v. 37, n. 33, p. 129-154, 2015.

Recebido em: 30/01/2019.

Aceito em: 30/03/2019.

\section{POLÊM!CA $\mid$ LABORE}

Polêmica - Revista Eletrônica da Uerj - Rua São Francisco Xavier, 524, $1^{\circ}$ andar bloco D, sl.1001 • Tels.: +55 21 2334-4088 / 4087 • http://www.e-publicacoes.uerj.br/index.php/polemica/index http://www.labore.uerj.br • laboreuerj@yahoo.com.br 